\title{
Use of serology and real time PCR to control an outbreak of bovine brucellosis at a dairy cattle farm in the Nile Delta region, Egypt
}

Mayada Gwida ${ }^{1,3^{*}}$, Maged El-Ashker ${ }^{2,3}$, Falk Melzer ${ }^{3}$, Mohamed El-Diasty ${ }^{4}$, Mohamed El-Beskawy ${ }^{2}$ and Heinrich Neubauer ${ }^{3}$

\begin{abstract}
Background: Bovine brucellosis remains one of the most prevalent zoonotic infections affecting dairy cattle in developing countries where the applied control programs often fail. We analyzed the epidemiologic pattern of bovine brucellosis in a dairy cattle herd that showed several cases of abortions after regular vaccination with RB51 (B. abortus vaccine). In 2013 thirty dairy cows, from a Holstein-Friesian dairy herd with a population of 600 cattle, aborted five months post vaccination by a regular RB51 vaccine. Blood samples were drawn from milking cows and growing heifers, as well as heifers and cows pregnant up to 6 months. These samples were collected in June 2013 $(n=257)$ and May $2014(n=263)$ and were tested by real time $(r t)-P C R$ as well as serological tests, in particular Rose Bengal Test (RBT), Enzyme-Linked Immunosorbent Assays (ELISA) and Fluorescence Polarization Assay. Tissue specimens were also collected from an aborted fetus and cultured. Isolates were subjected to bacteriological typing tests at the genus and species levels.
\end{abstract}

Results: Five months post vaccination with RB51 vaccine, Brucella (B.) DNA was detected in blood samples of cows by rt-PCR. The serological tests also revealed the spread of Brucella field strains within the herd in 2013. Four Brucella isolates were recovered from specimens collected from the aborted fetus. These isolates were typed as follows: one B. abortus RB51 vaccine strain and three isolates of $B$. abortus field strain. The seropositive cows with positive rt-PCR might indicate an infection by the Brucella field strain; while the positive rt-PCR results from seronegative animals may either be due to circulating RB51 vaccine DNA in vaccinated animals or to circulating field strain in infected animals before seroconversion.

Conclusion: The results herein suggest that PCR can be a good supplementary tool in an outbreak situation, if an assay is available that can differentiate vaccine and field strains with a high analytical sensitivity. We recommend using RBT and ELISA in parallel in outbreak situations, to identify as many infected animals as possible during the initial screenings. This test procedure should be repeated for at least three successive negative tests, with one month interval.

Keywords: Brucellosis, Cattle, Serology, RT-PCR, Public Health, Egypt

\footnotetext{
* Correspondence: mayada.gwida@gmail.com

'Department of Hygiene and Zoonoses, Faculty of Veterinary Medicine,

Mansoura University, Mansoura 35516, Egypt

${ }^{3}$ Friedrich-Loeffler-Institute (FLI), Institute of Bacterial Infections and

Zoonoses, 07743 Jena, Germany

Full list of author information is available at the end of the article
} 


\section{Background}

Brucellosis, caused by Brucella species, is considered one of the most common bacterial zoonotic infections worldwide. The infection is endemic in many geographic areas including the Mediterranean and Middle East regions, Indian subcontinent, Mexico and parts of central and South America [1,2]. The disease is a major cause of direct economic loss and impedes trade among countries [3]. The estimated annual economic loss due to brucellosis was about 60 million Egyptian pounds in 1995 [4]. The diagnosis of Brucella infection is usually based on clinical presentation, microbiological culture and demonstration of specific antibodies [5]. Despite being the more commonly used technique for the initial screening of the infection, serological tests have limitations because not all infected animals produce detectable levels of antibodies, and false-positive results are seen due to cross-reactivity with antigens of other bacterial species [6]. The sensitivity of bacteriological culture usually depends on the viability and number of Brucella in the sample, as well as contamination of the sample with other bacteria [7]. Conversely, culture methods are timeconsuming and the handling of microorganisms is hazardous [5]. In order to overcome most of these difficulties, PCR and real-time (rt)-PCR assays have been employed for diagnosis and molecular typing of Brucella species. Various PCR assays targeting different gene loci have been successfully used for diagnosis of brucellosis [8-12]. Species identification and sub-typing of Brucella isolates are very important not only for epidemiologic surveillance, but also for investigation of outbreaks in brucellosis endemic regions $[13,14]$. Multiple-Locus Variable number tandem repeat Analysis (MLVA) is a useful tool for identifying and genotyping of Brucella isolates and data could be used for epidemiological trace back investigations $[15,16]$.

Bovine brucellosis remains one of the most common zoonoses in Egypt, and causes great constraints to the Government in improving animal productivity. Although nearly a century has passed since the first description of Brucella in Egypt, it has not been possible to eradicate this infection. The enforcement of control measures for brucellosis in Egypt (test and slaughter, S19 vaccination) have led to a reduction of $B$. abortus incidence in cattle [17]. However, most of these endeavors are still not conclusive [17, 18]. Despite being endemic, little is known about the epidemiological situation of brucellosis among Egyptian dairy herds. Indeed, Brucella infection remains under-diagnosed and often underestimated. In general, the control programs of Brucella infection in animals relies mainly on vaccination with live attenuated B. abortus strain 19. This provides good levels of protection against $B$. abortus in cattle and B.melitensis Rev. 1is used in sheep and goats $[19,20]$. When administered correctly, the two vaccines can protect livestock from brucellosis, but the vaccines still have a drawback as they retain pathogenicity and sometimes cause abortion in vaccinated animals [21] and debilitating illness in humans [22-24]. In 2006, RB51, a mutant vaccine rough strain that is devoid of the lipopolysaccharide O-side chain was developed [25]. Cattle vaccinated with this kind of vaccine remained negative in conventional brucellosis serological tests [26]. This vaccine was suggested to be more appropriate than B. abortus S19 for the control and eradication programs that relied on serological testing and removal of positive animals [27].

For the effective monitoring of bovine brucellosis, it is imperative to have reliable tests to differentiate between vaccine and field strains. Thus, many molecular approaches have been developed to detect vaccine strains [28, 29]. Although extensive reports of animal brucellosis in Egypt are currently available, the epidemiologic situation of this infection is still ambiguous and needs further investigations. The purpose of this study was to analyze the epidemiologic pattern of bovine brucellosis in a well managed dairy farm in Egypt through a two year study period.

\section{Methods}

\section{Farm description and problem identification}

In 2013, a string of abortions $(n=30)$ was reported in a commercial dairy farm with a stock population of 600 Holstein-Friesian cattle. The farm's records indicated that the farm was free from brucellosis since 2008. All animals tested negative using Rose Bengal Test (RBT) and Buffered Acidified Plate Agglutination Test (BAPAT) and the farm was considered an "ideal" dairy farm. This means all effective health care programs were enforced. All "good dairy farming" practices for animal health are practiced under the following guidelines: preventing the entry of disease onto the farm, having an effective herd health management program in place, and using all chemicals and veterinary medicines as directed. The farm is located in Gamasa City on the coast of the Mediterranean Sea, Dakahlia Governorate, Egypt.

The main target groups of this study were milking cows, growing heifers plus heifers and cows being pregnant up to 6 months. The age of these animals ranged between 6 - to -18 months for heifers, and 2- to- 5 years for pregnant and non pregnant cows. A routine investigation for Brucella infection was performed with cattle at this farm in December 2012 using RBT and BAPAT and all cattle tested negative. For this reason, all animals (except those being pregnant $>3$ months; $n=80$ ) were vaccinated with RB51 (B. abortus vaccine, Professional Biological Company, USA) at the beginning of January 2013 according to the instructions of the manufacturer. Thirty cows aborted in June 2013. As a result of this, 
the pregnant heifers ( $<6$ months) and all cows (except those pregnant in the third trimester) were sampled for detailed serological and molecular investigations of Brucella infection. With the exception of abortion, no other clinical signs appeared in these animals during sampling. All animals on the farm remained clinically healthy without any detectable illness. During the period of abortions, the farm veterinarian exhibited some brucellosis related signs of infection including undulated fever, back and joint pain.

\section{Samples collection Blood samples}

The target groups of animals were sampled twice: in June $2013(n=257)$ and May $2014(n=263)$. Each time, ten $\mathrm{ml}$ of blood was collected through jugular vein puncture into vacutainer tubes without anticoagulant for separation of blood serum. The collected sera were serologically examined by RBT, Enzyme-Linked Immunosorbent Assays (ELISA) and Fluorescence Polarization Assay (FPA) at Friedrich-Loeffler-Institute (FLI), OIE reference laboratory in Jena. RBT was performed as previously described in the Manual of Standards for Diagnostic Tests and Vaccines [6] using antigen obtained from Institute Pourquier, France. Positive and negative control sera were the German national reference sera standardized according to OIE. The ELISA was performed and results were interpreted according to the instructions of the manufactures using IDEXX ${ }^{\mathrm{Tm}}$ Brucella ELISA kit (Montpellier SAS, France). FPA was done and results were interpreted according to the instructions of the manufacturer (Diachemix, Whitefish Bay, WT, USA). A blood sample was also drawn from the farm veterinarian and was tested by RBT, ELISA, FPA and rtPCR. Cultural procedures and molecular diagnostic assays were also performed at FLI, Jena, Germany. An informed consent for Brucella investigation was given by the owners. All procedures were performed in accordance with the principles and specific guidelines presented in the Guidelines for the Care and Use of Agricultural Animals in Research and Teaching, $3^{\text {rd }}$ ed. (http://www.fass.org/docs/agguide3rd/Ag_Guide_3rd_ed.pdf), and those of Mansoura University Animal Care and approved by its Ethical Committee.

\section{Tissue specimens}

Abomasal contents, liver, kidney and spleen were collected from an aborted fetus in June 2013 for isolation of Brucella organism. All tissue samples were cooled immediately after being collected, and were immediately transported to the laboratory. The collected specimens were cultured and subjected to the commonly used bacteriological typing tests at the genus and species (biovar) levels by classical microbiological methods [30].

\section{DNA preparation}

Genomic bacterial DNA was extracted and purified from collected sera $(n=520)$ as well as bacterial isolates using DNeasy Blood and Tissue Kit (QIAGEN, Germany) according to the instructions of the manufacturer using a QIAcube pipettor. DNA concentration was determined photometrically using a Nano Drop ND-1000 UV-Vis spectrophotometer (Nano-Drop Technologies, Wilmington, DE, USA).

\section{PCR amplification}

The extracted DNA was used for performing rt- PCR to detect the genus specific Brucella cell surface salt extractable bcsp31 $\mathrm{kDa}$ protein gene, B. abortus alkB gene and B. melitensis BMEI1162 gene [31]. The primers and TaqMan probes utilized for the assay were shown in Table 1. The rt- PCR assay was prepared using the TaqMan $^{\text {nt }}$ Environmental Master Mix (Applied Biosystems, New Jersey USA) containing the following components per reaction: $12.5 \mu \mathrm{l} \mathrm{TaqMan}^{\mathrm{Th}}$ Environmental Master Mix (Applied Biosystems), $0.5 \mu \mathrm{l}$ of each primer $(0.2 \mu \mathrm{M})$ and $0.25 \mu \mathrm{l}$ of each probe $(0.1 \mu \mathrm{M})$. Two $\mu \mathrm{l}$ of bacterial DNA was used as target and nuclease-free water sum up to a total reaction volume of $25 \mu \mathrm{l}$. Negative Template Controls (NTC) that contained $2 \mu \mathrm{l}$ of water instead of DNA and positive controls that contained DNA of Brucella were included in each run to detect any amplicon contamination or amplification failure. The rt - PCR reaction was performed in duplicate in optical 96-well microtitre plates (q PCR 96-well plates, Micro Amp TM, Applied Biosystem) using a Mx3000P thermocycler system (Stratagene, La Jolla, Canada) using the following reaction condition; initial denaturation at $95^{\circ} \mathrm{C}$ for $10 \mathrm{~min}$, followed by 50 cycles of $95{ }^{\circ} \mathrm{C}$ for $25 \mathrm{~s}$ and $57{ }^{\circ} \mathrm{C}$ for $1 \mathrm{~min}$. The samples scored positive confirmed by visual inspection of the graphical plots showing cycle numbers versus fluorescence values. A sample with a fluorescence signal 30 times greater than the mean standard deviation in all wells over cycles 2 through 10 was considered a positive result, whereas a sample yielding a fluorescence signal less than this threshold value was considered a negative result. Cycle threshold values below 39 cycles were interpreted as positive.

\section{Molecular identification of bacterial isolates}

Species identification of Brucella isolates was performed by using AMOS PCR [32]. The "Bruce-ladder PCR" was applied to identify the vaccine strain [33]. MLVA was also done to genotype the obtained isolates according to the previously described method using the MLVA-16 genotyping protocol [34]. Repeat numbers were calculated based on allele sizes measured by 
Table 1 Oligonucleotide primers and probes used in the real-time PCR assay for the detection of Brucella spp., B. abortus, and B. melitensis

\begin{tabular}{|c|c|c|c|}
\hline Target & Primer & & \\
\hline \multirow[t]{3}{*}{ Brucella spp. } & 5 'GCTCGGTTGCCAATATCAATGC 3’' & Forward & Jena Bioscience GmbH, Germany \\
\hline & 5 'GGGTAAAGCGTCGCCAGAAG 3’ & Reverse & \\
\hline & AAATCTTCCACCTTGCCCTTGCCATCA 6-FAM/BHQ1 & Probe & \\
\hline \multirow[t]{3}{*}{ B. abortus } & 5'GCGGCTTTTCTATCACGGTATTC 3’ & Forward & \\
\hline & 5'CATGCGCTATGATCTGGTTACG 3’' & Reverse & \\
\hline & CGCTCATGCTCGCCAGACTTCAATG HEX/BHQ1 & Probe & \\
\hline \multirow[t]{3}{*}{ B. melitensis } & 5`AACAAGCGGCACCCCTAAAA 3’ & Forward & \\
\hline & $5^{\circ}$ CATGCGCTATGATCTGGTTACG 3’' & Reverse & \\
\hline & CAGGAGTGTTTCGGCTCAGAATAATCCACA CY5/BHQ2 & Probe & \\
\hline
\end{tabular}

6-FAM 6-carboxyfluorescein, HEX 6-hexachlorofluorescein, BHQ1 Black Hole Quencher 1, BHQ2 Black Hole Quencher 2

capillary electrophoresis (Applied Biosystems ${ }^{\oplus} 3130$ Genetic Analyzer) according to the previously described procedure [35].

\section{Results}

Brucella infection was diagnosed in the farm by using various serological and molecular techniques. The detailed results of serology as well as molecular diagnostic assays were reported in Tables 2 \& 3 . Briefly, one hundred twenty three samples (47.9\%) were found to be negative by using all serologic tests and rt-PCR; while $6.6 \%(n=17)$ yield positive by all serological tests in combination with rt-PCR at genus and species levels.

Table 2 Detailed results of different serological tests and real time PCR for the detection of Brucella infection among cattle population during two years study period

\begin{tabular}{|c|c|c|c|c|c|c|}
\hline & $n$ & RBT & ELISA & FPA & $\begin{array}{l}\text { Bcsp31 PCR } \\
\text { (Brucella genus) }\end{array}$ & $\begin{array}{l}\text { AlkB PCR } \\
\text { (B. abortus) }\end{array}$ \\
\hline \multirow{10}{*}{$\begin{array}{l}\text { Animals examined } \\
\text { in } 2013(n=257)\end{array}$} & 123 & neg & neg & neg & neg & \\
\hline & 95 & neg & neg & neg & pos & pos \\
\hline & 17 & pos & pos & pos & pos & pos \\
\hline & 6 & neg & pos & neg & pos & pos \\
\hline & 2 & neg & pos & pos & pos & pos \\
\hline & 4 & neg & neg & sus & neg & na \\
\hline & 5 & pos & neg & neg & neg & na \\
\hline & 2 & pos & pos & pos & neg & na \\
\hline & 2 & neg & pos & sus & neg & na \\
\hline & 1 & neg & neg & pos & neg & na \\
\hline \multirow{4}{*}{$\begin{array}{l}\text { Animals examined } \\
\text { in } 2014(n=263)\end{array}$} & 1 & neg & neg & sus & neg & na \\
\hline & 2 & neg & pos & pos & neg & na \\
\hline & 1 & neg & pos & sus & neg & na \\
\hline & 259 & neg & neg & neg & neg & \\
\hline
\end{tabular}

$n$ number, neg negative, pos positive, susp suspicious, na not applicable
ELISA, RBT and FPA also revealed the spread of Brucella field strains within the herd in 2013; their respective percentages were $11.3,9.3$ and 8.6 (Table 2). However, $36.96 \%$ of the tested samples $(n=95)$ were seronegative but gave positive by rt-PCR where the only species identified was $B$. abortus.

Four Brucella isolates were recovered from the collected four specimens of the aborted fetus. These isolates were typed as one vaccine strain (from liver specimens) and three isolates of $B$. abortus field strain (from spleen, abomasum and genital organs) by using Bruce-ladder PCR (Table 3) while B. abortus was confirmed by AMOS PCR. The three field strain isolates showed the same MLVA-16 genotype. B. abortus was also identified in the sample of the farm veterinarian on the basis of a combination of serological tests (RBT, ELISA and FPA) and rt-PCR assay. Cows that were positive in at least two serological tests or one serological test plus the rt-PCR $(n=27)$ were removed from the farm in July 2013 while RB51 vaccine was further administered to all non pregnant heifers and parturient cows (30-45 days post calving). In May 2014, two hundred and sixty three samples gave negative results by using rt-PCR, RBT, ELISA and FPA; while three samples were seropositive.

\section{Discussion}

Among the bacterial zoonoses affecting dairy cattle in developing countries, bovine brucellosis is considered the most prevalent infection when the applied control programs have failed. The infection poses not only a risk to animals, but also represents a zoonosis with debilitating illness and severe complications in humans. In Egyptian control programs for brucellosis, RB51 B. abortus vaccine is believed to be cleared from the blood stream within three days but can sporadically induce late term abortions if administered to pregnant cows [36]. The agent can then persist in infected tissues of the cow 
Table 3 Characterisation of Brucella isolates of tissue specimens collected from an aborted fetus

\begin{tabular}{|c|c|c|c|c|}
\hline origin & Conventional methods & Brucella-PCR & Amos-PCR & Ladder-PCR \\
\hline Liver & B. abortus & Positive & B. abortus & B. abortus vaccine strain \\
\hline Spleen & B. abortus & Positive & B. abortus & B. abortus field strain \\
\hline Abomasal contents & B. abortus & Positive & B. abortus & B. abortus field strain \\
\hline Genital organ & B. abortus & Positive & B. abortus & B. abortus field strain \\
\hline
\end{tabular}

and fetus/calf. The presence of Brucella DNA in blood samples of these rare cases was supposed to be due to intermittent bacteremia whereas the organism is located intracellularly and may result in a persistent infection for long time [37]. In the present study, an unexpected high number of rt-PCR positive blood samples were detected five months after routine vaccination. The ninety five seronegative cows with positive rt-PCR results may have had circulating rough RB51 vaccine strain DNA in their blood as some researchers were able to detect RB51 vaccine strain DNA for twenty five days in the milk of vaccinated buffaloes although cultivation was possible only for 4 days [38]. Longer circulation of vaccine DNA in the blood stream is therefore a realistic possibility for the origin of DNA found. The twenty five serologically positive cows that showed $B$. abortus DNA in their blood stream may have been infected by the field strain. However, the seropositive animals with negative rt-PCR results $(n=10)$ might represent animals at different stages of infection whenever the DNA is already cleared from the blood stream. The same suggestion was previously reported by Gwida et al. [39]

In general, the use of rt-PCR for the diagnosis of brucellosis from blood samples of ruminants has been discussed controversially. It has been supposed that the sensitivity of PCR is dependent on the status of disease i.e. the chronic infected animals are regularly misdiagnosed as no $B$. abortus DNA is present in respective samples [12]. The presence of $B$. abortus DNA was, however, demonstrated in blood samples from various infected animal species and humans but with varying sensitivities [9, 40, 41]. Recently, B. abortus and $B$. melitensis DNA were detected in bovine milk which was collected from apparently healthy animals by using species-specific IS711 rt-PCR [42]. It has been shown that rt-PCR could be an additional tool in an outbreak situation when serological methods are still negative or it might help to identify animals which are not detected by conventional serological methods [40].

The coincidence of vaccination and the apparent infection by a field strain in this herd which was serologically negative two months prior to the administration of the vaccine highlights the fact that RB51 vaccination cannot protect a herd (or single animals) from being infected with $B$. abortus in an endemic area. Vaccination may only reduce economical loss for the farmer. The sense of security conveyed by vaccination may even result in loss of awareness and impaired biosecurity. It was previously speculated that the vaccine strain can transmit from vaccinated animals to pregnant animals and cause abortion in very few cases [36]. Our findings support such suspicions where vaccine and field strain are isolated from the same fetus, suggesting that transmission of RB51 vaccine strain from non pregnant animals to unvaccinated pregnant animals has taken place. Our screening system made sure that most of the female animals used for reproduction on the farm were investigated with all techniques during the investigation period of two years. Vaccination and serological investigation with subsequent removal of reactors may result in the absence of abortions from July 2013 to May 2015. Although, in the routine RBT and BAPAT screening at May 2014, three cows tested positive which were later on reactive in ELISA and FPA but negative in rt-PCR. Simply, these animals could be undetected due to the stage of infection or could be re-contaminated via new introduction of a field strain. As a special problem for eradication of brucellosis, are those female calves that were borne to Brucella positive mothers. These calves may harbor the agent during their childhood and first pregnancy and seroconvert after they have calved [43-45]. In the setting of Egypt, such animals can run undetectable for approximately 20 months. We strongly advice to remove all seropositive animals from the herd although the fact that few false positive reactors may be culled.

The farm veterinarian contracted the infection with $B$. abortus during his daily work on the farm, when he was not aware that the disease was introduced only recently. This finding highlights the public health hazard of Brucella infection and could be an alarm for the potential risks for personnel elsewhere. We were unable to detect the source of infection, or the way through which the agent was introduced into the farm. It is an accepted fact that even very well managed farms in endemic areas can easily become contaminated [40]. It is obvious that prevention of damage in endemic areas should involve the practices of good farm management for biosecurity and biosafety. Therefore, we highlighted some findings made during this outbreak. In general, vaccination using a vaccine which does not interfere with serology is advised. However, current vaccines can cause abortions even if all recommendations are followed. The animal owner has to be made aware of this drawback 
of vaccines, although it has to be stressed that the benefit of vaccination outweighs its risks. Routine screening with a sensitive and specific test (validation of test has to be done in the region where it will be used) in short intervals has to be applied. It is worthy to note that no further abortions were recorded at the farm, since applying the strategy of test and slaughter. By the end of April 2014, 120 cows were culled from the farm, being either seropositive or having concomitant ailments including mastitis, laminitis and metritis. Special concern should be directed to females of a Brucella infected mother or those females which have unknown background, as such animals can be a carrier of Brucella and may seroconvert after abortion or calving only.

\section{Conclusion}

We believe that RBT and BAPAT is a very useful combination of tests in Egypt, considering effectiveness and cost. If introduced, serological screening should be confirmed by ELISA and all reactors should be removed from the herd. All animals on the farm should be tested. We also suggest that PCR can be a good supplementary test for outbreak situations, as PCR can differentiate vaccine and field strains with high analytical sensitivity. We also recommend using RBT and ELISA in parallel in an outbreak situation to identify as many infected animals as possible during the initial screenings, and to repeat this test procedure for at least three successive negative tests with one month interval.

\section{Competing interests}

The authors of this paper hold no financial or personal relationships with individuals or organizations that would inappropriately influence or bias the findings of this paper.

\section{Authors' contributions}

MG designed and coordinated the study, carried out the experimental work, data analysis, was writing the manuscript, did the review of the final manuscript, got approval for publication and was responsible for all correspondence to the journal. MEA participated in sample collection and clinical examination of the animals, took part in writing of the manuscript, helped to draft the manuscript, reviewed the final manuscript and cooperated with MG to correspond to the journal. FM contributed to the study design and to draft the manuscript. MED and MEB participated in sample collection. HN participated in the design and coordination of the study, evaluation of the PCR assays and helped to draft and review the manuscript. All authors approved the final version of the manuscript for publication.

\section{Acknowledgement}

This work is funded by the German Federal Foreign Office program: Deutsches Partnerschaftsprogramm für biologische Sicherheit und Gesundheitssicherstellung. Special thanks are given to the Egyptian Ministry of High Education and Cultural Affairs and Missions sector for their encouragement and appreciated their cooperation regarding the post-Doctor scholarship given to the first author to FLI, Jena, Germany. The authors thank Keri Clack (Alere Technologies) as a native speaker for the improvement of the manuscript. Mr. Hosny El-Adawy has participated in performing some PCR assays.

\section{Author details}

'Department of Hygiene and Zoonoses, Faculty of Veterinary Medicine, Mansoura University, Mansoura 35516, Egypt. ${ }^{2}$ Department of Internal Medicine and Infectious Diseases, Faculty of Veterinary Medicine, Mansoura University, Mansoura 35516, Egypt. ${ }^{3}$ Friedrich-Loeffler-Institute (FLI), Institute of Bacterial Infections and Zoonoses, 07743 Jena, Germany. ${ }^{4}$ Animal Health Research Institute-Mansoura Provincial Laboratory, Mansoura, Egypt.

Received: 15 October 2015 Accepted: 16 February 2016

Published online: 24 February 2016

\section{References}

1. Roushan HMR, Mohraz M, Hajihamdi M, Ramzani A, Valayati AA. Efficacy of gentamicin plus doxycycline versus streptomycin plus doxycycline in the treatment of brucellosis in humans. Clin Infect Dis. 2006;42:1075-80.

2. Mantur BG, Amarnath SK. Brucellosis in India-a review. J Biosci. 2008;33:539-47.

3. Acha PN and Szyfres B. Zoonoses and communicable diseases common to man and animals. Pan American Health Organization Sci Publ. 2001.p. 40-62

4. AOAD. Arab organization for agriculture development report. December, Khartoum, Sudan. 1995. p. 414-74.

5. Refai M. Application of biotechnology in the diagnosis and control of brucellosis in the Near East Region. World J Microbiol Biotechnol. 2003;19:443-9.

6. OIE. Bovine brucellosis. Manual of Diagnostic Tests and Vaccines for Terrestrial Animals Office International des Epizooties, Paris. 2009.

7. Ilhan Z, Solmaz H, Aksakal A, Gulhan T, Ekin IH, Boynukara B. Detection of Brucella melitensis DNA in the milk of sheep after abortion by PCR assay. Arch Med Vet. 2008:40:141-6

8. Fekete A, Bantle JA, Halling SM, Sanborn MR. Preliminary development of diagnostic test for Brucella using PCR. J App Bacteriol. 1990;69:216-27.

9. Leal-Klevezas DS, Martínez-Vázquez IO, López-Merino A, Martínez-Soriano JP. Single-step PCR for detection of Brucella spp. from blood and milk of infected animals. J Clin Microbiol. 1995;33:3087-90.

10. Amin AS, Hamdy ME, Ibrahim AK. Detection of Brucella melitensis in semen using the polymerase chain reaction assay. Vet Microbiol. 2001;83:37-44.

11. Leyla G, Kadri G, Umran O. Comparison of polymerase chain reaction and bacteriological culture for the diagnosis of sheep brucellosis using aborted fetus samples. Vet Microbiol. 2003;93:53-61.

12. O'Leary S, Sheahan M, Sweeney T. Brucella abortus detection by PCR assay in blood, milk and lymph tissue of serologically positive cows. Res Vet Sci. 2006;81:170-6.

13. Al Dahouk S, Le Flèche P, Nöckler K, Jacques I, Grayon M, Scholz HC, et al. Evaluation of Brucella MLVA typing for human brucellosis. J Microbiol Methods. 2007:69:137-45.

14. Marianelli C, Graziani C, Santangelo C, Xibilia MT, Imbriani A, Rosa A, et al. Molecular epidemiological and antibiotic susceptibility characterization of Brucella isolates from humans in Sicily, Italy. J Clin Microbiol. 2007;45: 2923-8.

15. Kattar MM, Jaafar RF, Araj GF, Le Flèche P, Matar GM, Roland AR, et al. Evaluation of a multilocus variable-number tandem-repeat analysis scheme for typing human Brucella isolates in a region of brucellosis endemicity. J Clin Microbiol. 2008;46:3935-40.

16. Ferreira AC, Chambel L, Tenreiro T, Cardoso R, Flor L, Dias IT, et al. MLVA16 typing of Portuguese human and animal Brucella melitensis and Brucella abortus isolates. PLoS One. 2012;8:e42514. doi:10.1371/journal.pone.0042514.

17. Refai M. Incidence and control of brucellosis in the Near East region. Vet Microbiol. 2002;90:81-110.

18. Flores MB. Field experience with the control of Brucella melitensis from selected countries. In: Brucella melitensis in Eurasia and The Middle East, FAO. 2010; 10: 9.

19. Graves RR. The story of John M Buck's and Matilda's contribution to the cattle industry. J Am Vet Med Assoc. 1943;102:193-5.

20. Elberg SS, Faunce K. Immunization against Brucella infectionVI. Immunity conferred on goats by a nondependent mutant from a streptomycindependent mutant strain of Brucella melitensis. J Bacteriol. 1957;73:211-27.

21. Diptee MD, Adesiyun AA, Asgarali Z, Campbell M, Adone R. Serologic responses, biosafety and clearance of four dosages of $B$. abortus strain RB51 in 6-10 months old water buffalo (Bubalus bubalis). Vet Immunol Immunopathol. 2006;109:43-55.

22. Blasco JM. A review of the use of $B$. melitensis Rev. 1 vaccine in adult sheep and goats. Prev Vet Med. 1997;31:275-83. 
23. Van Metre DC, Kennedy GA, Olsen SC, Hansen GR, Ewalt DR. Brucellosis induced by RB51 vaccine in a pregnant heifer. J Am Vet Med Assoc. 1999; 215:1491-3.

24. Berkelman RL. Human illness associated with the use of veterinary vaccines. Clin Infect Dis. 2003;37:407-14.

25. Poester FP, Goncalves VSP, Paix OTA, Santos RL, Olsen SC, Schurig GG, et al. Efficacy of strain RB51 vaccine in heifers against experimental brucellosis. Vaccine. 2006;19:5327-34.

26. Robles CA, Nielsen K, Gall D, Willems P. Evaluation of three different antigens in an iELISA for the detection of antibodies against B. abortus RB51 in vaccinated heifers. Vet Immunol Immunopathol. 2009:127:153-5.

27. Abd El-Razik AK, Abd El-Hafez MS, Shell SW, Ghazi AY. The immunological response of RB51 vaccinated buffalo calves using brucella periplasmic proteins as ELISA antigen. Afr J Biotechnol. 2011;10:10562-6.

28. Cloeckaert A, Grayon M, Grépinet O. Identification of Brucella melitensis vaccine strain Rev.1 by PCR-RFLP based on a mutation in the rpsL gene. Vaccine. 2002;20:2546-50

29. Gopaul KK, Sells J, Bricker BJ, Crasta OR, Whatmore AM. Rapid and reliable single nucleotide polymorphism-based differentiation of Brucella live vaccine strains from field strains. J Clin Microbiol. 2010;4:1461-4.

30. Alton $\mathrm{GG}$, Jones $L M$, Angus RD, Verger JM. Techniques for the brucellosis laboratory. Paris, France: INRA; 1988.

31. Probert SW, Schrader NK, Khuong YN, Bystrom LS, Graves HM. Real-Time Multiplex PCR Assay for Detection of Brucella spp., B. abortus, and B. melitensis. J Clin Microbiol. 2004;42:1290-3.

32. Bricker BJ, Halling SM. Differentiation of Brucella abortus bv 1,2 , and 4 , Brucella melitensis, Brucella ovis, and Brucella suis bv. 1 by PCR. J Clin Microbiol. 1994;32:2660-6.

33. López-Goñi I, García-Yoldi D, Marín CM, de Miguel MJ, Muñoz PM, Blasco JM, et al. Evaluation of a multiplex PCR assay (Bruce-ladder) for molecular typing of all Brucella species, including the vaccine strains. J Clin Microbiol. 2008;46:3484-7.

34. Le Flèche P, Jacques I, Grayon M, Al Dahouk S, Bouchon P, Denoeud F, et al. Evaluation and selection of tandem repeat loci for a Brucella MLVA typing assay. BMC Microbiol. 2006;6:9.

35. Garofolo G, Ancora M, Di Giannatale E. MLVA-16 loci panel on Brucella spp. using multiplex PCR and multicolor capillary electrophoresis. J Microbiol Methods. 2013;92:103-7.

36. Dougherty A, Cornish ET, Toole D, Boerger-Fields A, Henderson O, Mills K. Abortion and premature birth in cattle following vaccination with Brucella abortus strain RB51. J Vet Diagn Invest. 2013;25:630-5.

37. Ganado W, Bannister W. Bacteraemia in human brucellosis. BMJ. 1960;1:601-3.

38. Longo M, Mallardo K, Montagnaro S, De Martino L, Gallo S, Fusco G, et al. Shedding of $B$. abortus rough mutant strain RB51 in milk of water buffalo (Bubalus bubalis). Prev Vet Med. 2009;90:113-8

39. Gwida M, El-Gohary A, Melzer F, Tomaso H, Rösler U, Wernery U, et al. Comparison of diagnostic tests for the detection of Brucella spp in camel sera. BMC Res Notes. 2011:4:525.

40. Guarino A, Serpe L, Fusco G, Scaramuzzo A, Gallo P. Detection of Brucella species in buffalo whole blood by gene-specific PCR. Vet Rec. 2000;147:634-6.

41. Ghoneim N, Zeedan G, Ghazy A, Abdalhamed A. Molecular and Serological detection of the most common Brucella species infection in bovine and human in Egypt. IJAR. 2014;2:217-26.

42. Wareth G, Melzer F, Elschner MC, Neubauer H, Roesler U. Detection of Brucella melitensis in bovine milk and milk products from apparently healthy animals in Egypt by real-time PCR. J Infect Dev Ctries. 2014;8:1339-43.

43. Christie TE. Eradication of brucellosis in Northern Ireland: field problems and experience. Vet Rec. 1969;85:268-9.

44. Wilesmith JW. The persistence of Brucella abortus infection in calves: a retrospective study of heavily infected herds. Vet Rec. 1978;103:149-53.

45. Lapraik RD, Moffat R. Latent bovine brucellosis. Vet Rec. 1982;18:578-9. 